\title{
FOTOGRAFÍAS DE ARQUITECTURAY ARQUITECTURA DE FOTOGRAFÍAS A COMIENZOS DEL SIGLO XX
}

Nicole Halm

Ma. Emilia Deus
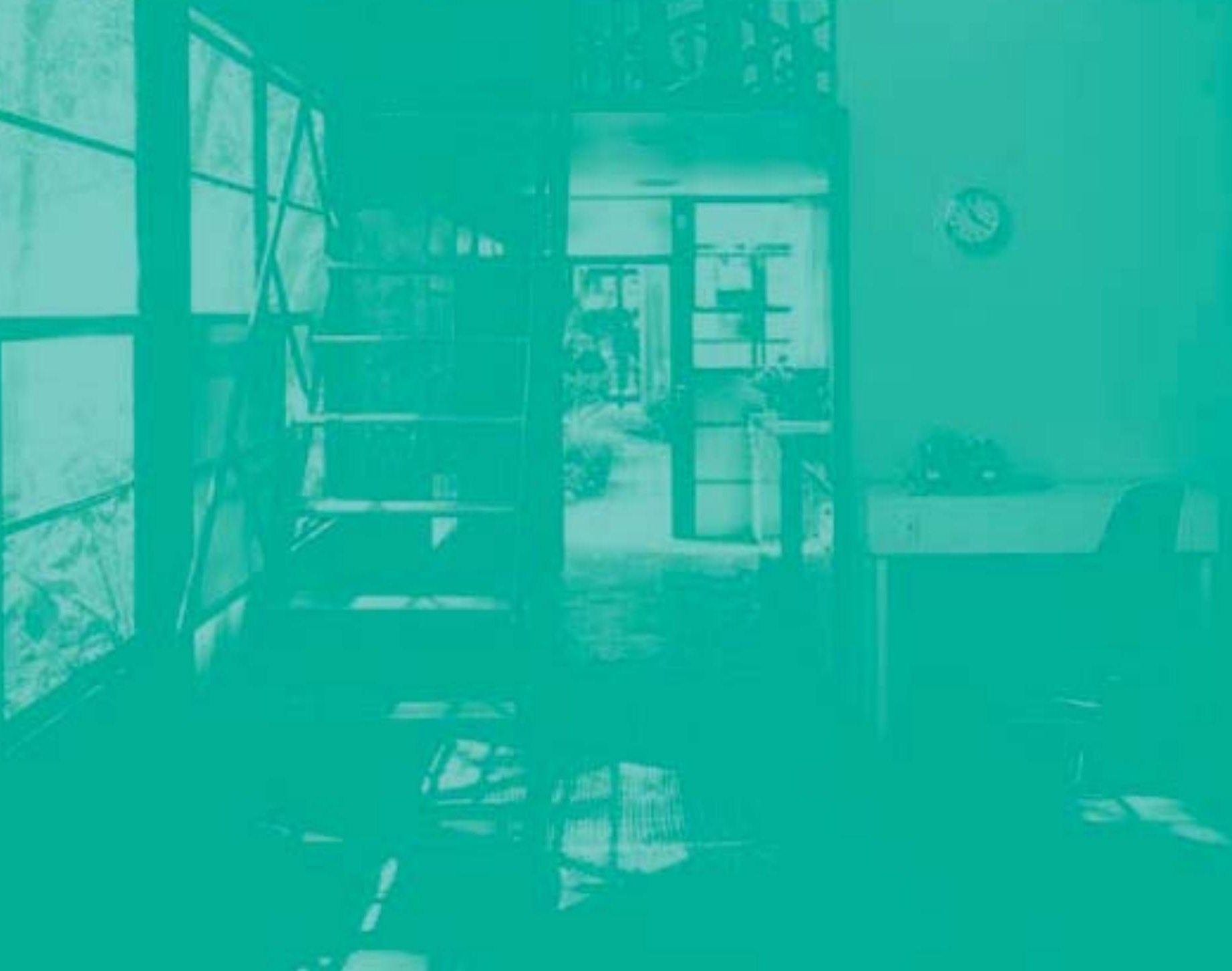


\section{NICOLE HALM}

Arquitecta. Facultad de Arquitectura, Universidad ORT Uruguay. Actividad profesional independiente.

\section{MA. EMILIA DEUS}

Arquitecta. Facultad de Arquitectura, Universidad ORT Uruguay. Actividad profesional independiente. 


\section{RESUMEN}

A partir del siglo XX la relación de la fotografía y la arquitectura ha cobrado un nuevo sentido; dos disciplinas independientes comienzan a actuar conjuntamente para posteriormente fusionarse en una sola.

Por un lado, se considera a la arquitectura como medio compositivo, donde la fotografía es quien trasciende mientras que la primera se comporta como objeto fotográfico. Por otro lado, se considera a la fotografía como herramienta esencial en la construcción del imaginario colectivo para la promoción de la arquitectura.

La fotografía colaboró en la consolidación de algunos de los maestros de la arquitectura moderna, en los que el trabajo conjunto de arquitecto y fotógrafo produjo destacados fenómenos mediáticos de gran éxito internacional. Dentro de ellos resalta la figura del arquitecto Le Corbusier como fotógrafo durante su primera etapa, como también del fotógrafo Julius Shulman trabajando junto al programa Case Study Houses.

Palabras Clave: Hacia la arquitectura moderna, Le Corbusier, Julius Shulman, Ville Savoye, Case Study Houses, fotografía de arquitectura, composición de fotografías.

\section{ABSTRACT}

From the twentieth century the relationship of photography and architecture assumes a new role; two independent disciplines start working together to subsequently merge into one.

On the one hand, architecture is considered as a compositional medium, where photography transcends while the former behaves as a photographic object. On the other hand, photography is meant to be an essential tool in the construction of the collective imagination for the promotion of architecture.

Photography collaborated in the consolidation of some of the masters of modern architecture, in which the joint work of architect and photographer produced outstanding media phenomena with international success. Among them is the figure of the architect Le Corbusier as a photographer during his first phase, as well as the photographer Julius Shulman working alongside the Case Study Houses Program.

Keywords: Towards modern architecture, Le Corbusier, Julius Shulman, Ville Savoye, Case Study Houses, architecture photography, composition of photographs. 


\section{HACIA LA ARQUITECTURA MODERNA}

En el primer tercio del siglo XX surgieron nuevos cuestionamientos sobre las leyes que definían el arte. Se abandona el interés sobre las cuestiones internas de cada disciplina y se replantea el sentido del arte. Es así que el rol del artista varía sustancialmente, ya que su figura se presenta como el ser creativo que puede experimentar a través de nuevos medios.

La Primera Guerra Mundial desencadenó un estado de crisis que no solo repercutió en las artes plásticas y visuales, sino también en la fotografía y la arquitectura. Es así, que en esta primera mitad del siglo XX, más precisamente en la década del 20, se inicia una búsqueda para la redefinición del concepto de modernidad. Independientemente una de la otra, fotografía y arquitectura evolucionaron ante estos cambios, sin embargo dicha evolución se dio en forma similar, al detectarse parámetros en común. La arquitectura dejó de ser un simple objetivo para la fotografía para convertirse en su musa, que posa y se prepara para ser fotografiada. Asimismo, ésta encuentra en ella una oportunidad para su promoción mediática. Por lo tanto, es a partir de este cambio que la fotografía se convierte en el medio más idóneo y directo para expresar el espíritu del movimiento moderno.

La fotografía era capaz de suprimir los límites físicos y temporales, que representaban obstáculos para los artistas. No es casualidad, que el desarrollo de la fotografía de arquitectura fuera acompasado de los cambios que había traído la modernidad, de la necesidad de lo extra-local, la expansión de los límites, los grandes viajes, el intercambio y por sobre todo la comercialización. Es así, que se generó una riqueza de registros de imágenes que excedía lo que se había dado hasta entonces con otros medios de reproducción visual.

En los años treinta el imaginario estaba dominado por la máquina. Estos años treinta eran como la coronación de la revolución industrial. La propia cámara fotográfica era vista como un máquina, una extensión de ese nuevo mundo tecnológico. No había mejor medio para captar a la ciudad moderna como una máquina fot gráfica. No existía medio más adecuado que la cámara para documentar los rascacielos y el paisaje urbano durante los años de la década de 1930 (Colorado, 2011, párr. 15).

Reyner Banham (1989) observó que el Movimiento Moderno era el primer movimiento basado exclusivamente en la evidencia fotográfica más que en la experiencia personal o en los libros convencionales. La obra de varios arquitectos se dio a conocer en la mayoría de los casos a través de publicaciones impresas y fotografías. Este hecho conduce a un cambio en el quehacer arquitectónico. Paradójicamente, la arquitectura se vuelve más inmaterial, pero no en el sentido literal, sino que el nuevo lugar de producción ya no es la construcción sino las publicaciones, revistas o exposiciones. 


\section{LE CORBUSIER: EL ARQUITECTO FOTÓGRAFO}

La obra de Le Corbusier, es un claro ejemplo de la relación que existe entre la arquitectura moderna y los medios de comunicación. Éste visualizó a través de las publicidades de los productos industriales de la época que el modo más directo para hacer llegar la arquitectura a las masas era a través de los medios visuales, $y$ principalmente de los medios de comunicación.

Le Corbusier discernió que con la ayuda de las nuevas tecnologías de los medios de comunicación, los arquitectos son los únicos capaces de crear o manipular las percepciones de la realidad (Colomina, 2010). Como arquitecto, prefería expresarse a través de la imagen, ya que sostenía que era un medio más rápido y más sincero, además que le permitía expresar un futuro no necesariamente real, que podía ser imaginario y aun así no dar lugar a la mentira (Lahuerta, 2010).

“La arquitectura es el juego sabio, correcto y magnífico de los volúmenes reunidos bajo la luz. Nuestros ojos están hechos para ver las formas bajo la luz: las sombras y los claros revelan la forma" (Le Corbusier, 1998, p. 16).

Según Le Corbusier (1999) existían dos espacios válidos para la arquitectura: el espacio tridimensional (el real) y el espacio bidimensional (la fotografía), pero elegía valerse sólo del segundo. Para Le Corbusier una vez construida la arquitec-

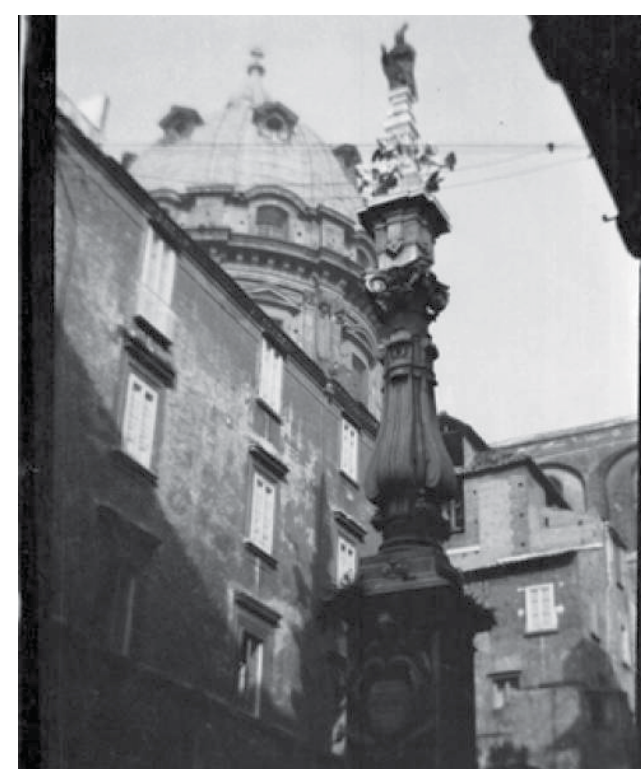

Figura 01.

Fotografía en Italia sacada por Le Corbusier durante su Viaje en Oriente.

Fotógrafo: Le Corbusier, 1910.
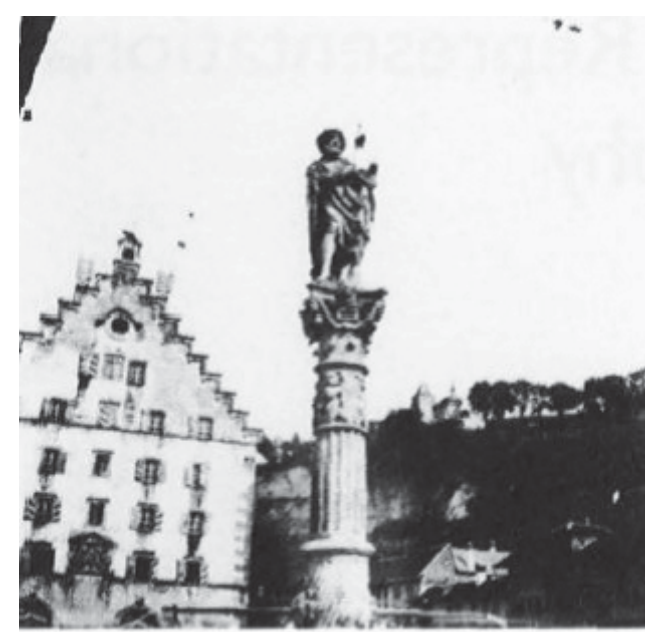

Figura 02

Fotografía en Alemania sacada por Le Corbusier en su Viaje en Oriente.

Fotógrafo: Le Corbusier, 1910. 


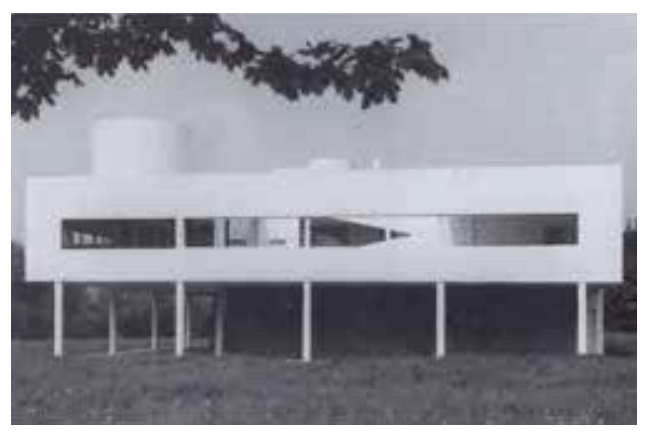

Figura 03.

Vista Frontal Ville Savoye, Poisy, Francia.

Fotógrafo: Le Corbusier, 1929.

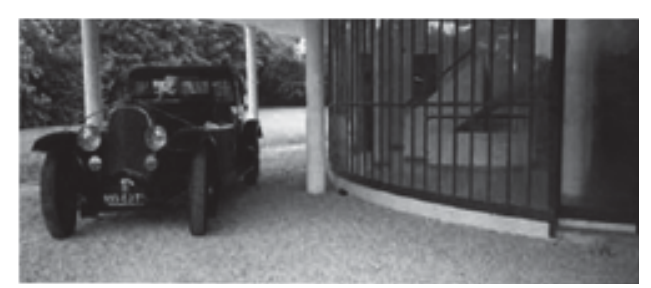

Figura 04.

Ville Savoye. Vehículo ingresando en la planta baja. Fotógrafo: Le Corbusier, 1929. tura, su única salvación era ingresar al espacio bidimensional para poder ser devuelta al mundo de las ideas, y esto era posible gracias a la fotografía, valiéndose de la misma no como modo representativo, sino para transformar el sentido fundamental del espacio (Le Corbusier, 1999).

Este criterio convierte a su arquitectura en una cuestión conceptual, donde adquiere mayor solidez en el mundo de las ideas que en el mundo construido. Por lo tanto, resulta evidente que para Le Corbusier cualquier imagen manipulada que reflejase mejor el concepto de la obra, era preferible a la imagen fiel de la obra construida:

\section{LA VILLE SAVOYE}

Esta obra es la celebración más satisfactoria de los cinco puntos de una nueva arquitectura, y por tanto la materialización de la famosa máquina de habitar, paradigma de la arquitectura moderna. Si bien es posible realizar una descripción arquitectónica de la casa, descubriendo los cinco puntos en sus componentes, el foco central de este estudio es descubrir el discurso teórico del arquitecto a través del objeto mismo, utilizando como medio a la fotografía. Por lo tanto, el centro de atención no es la casa en sí, sino la imagen de la Ville Savoye, como si se trabajase sobre un anuncio publicitario. Ésta se constituye más como un relato de los ideales de Le Corbusier, que como un objeto en sí. La Ville Savoye parece haber sido construida más en función de cómo sería vista, más que de cómo sería habitada. 
Fue recién con la Villa Savoye que Le Corbusier logra desarrollar con madurez el concepto de promenade arquitectónica. La casa se presentaba como un verdadero paseo arquitectónico. Si bien su esquema general era bastante riguroso (una malla cuadrada de pilotis distanciados por 4,75 metros), Le Corbusier logró generar un recorrido dinámico, ofreciendo perspectivas que se encontraban en constante cambio o en algunos casos hasta resultaban inesperadas.

La promenade en la Ville Savoye comenzaba desde que se ingresaba al edificio, pudiendo ser rápidamente reconocible el itinerario pautado por el arquitecto. La planta baja de la casa fue diseñada para que al llegar con el auto, el volumen curvo presente en la misma, coincidiera con el radio de giro del vehículo. De esta modo, esta circulación tipo caracol, dejaba posicionado al usuario ante la entrada de acceso a la vivienda, que se realizaba a través de una rampa o también una escalera presente en dicho volumen curvo.

Una vez dentro de la casa, el recorrido continuaba hasta la azotea a través de un sistema de rampas interiores y exteriores. Le Corbusier encontraba en la rampa un gran medio para colaborar con la promenade, ya que ésta garantizaba al usuario un recorrido constante. La rampa era la línea guía que conducía al usuario desde el comienzo del recorrido (primera planta) hasta el final (azotea). Si se analiza con detención, se puede deducir que el paseo está organizado en vertical, como si Le Corbusier se lo hubiese ima- ginado en una sección cuando lo dibujó. Esto demuestra la gran importancia que tenía la sección para el arquitecto, prefiriéndola por sobre la planta, ya que la primera podía dar cuenta del dinamismo del espacio y las relaciones entre los distintos niveles, acorde a la estructura abierta que planteaba la nueva arquitectura.

Si bien se podría decir que el carácter secuencial de recorrido aproxima a la Ville Savoye a una concepción cinematográfica, cada pausa en dicho recorrido se asimila a una fotografía.

Otro punto a destacar es que las personas que aparecen en las fotografías de las villas de Le Corbusier, se muestran en una actitud de visitantes. Se recurre a la incorporación de personas sólo para enfatizar los recorridos, nunca para demostrar la habitabilidad del lugar. Por el contrario, como sucede también en las fotografías, Le Corbusier rara vez muestra personas, ya que apartarían la atención del objeto arquitectónico. Una de las escenas más figurativas de este concepto, es la de la mujer recorriendo la Ville Savoye por la rampa. El personaje se muestra siempre anónimo, lo único reconocible es la arquitectura.

El foco no siempre estaba impuesto exclusivamente en el objeto arquitectónico sino que Le Corbusier también recurría a estrategias para manifestar el tipo de hombre que debía hacer uso de su arquitectura. Es por tal, que se puede detectar en algunas fotografías de los interiores de la Ville Savoye la presencia de objetos 


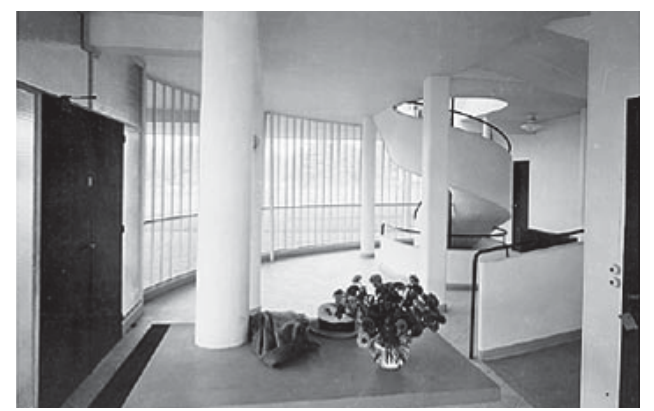

Figura 05.

Ville Savoye. Vestíbulo.

Fotógrafo: Le Corbusier, 1929.

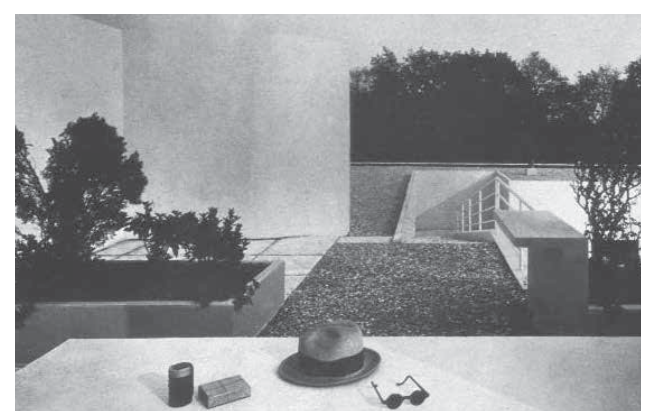

Figura 06.

Ville Savoye. Vista desde fachada norte, cubierta-jardín.

Fotógrafo: Le Corbusier, 1929.

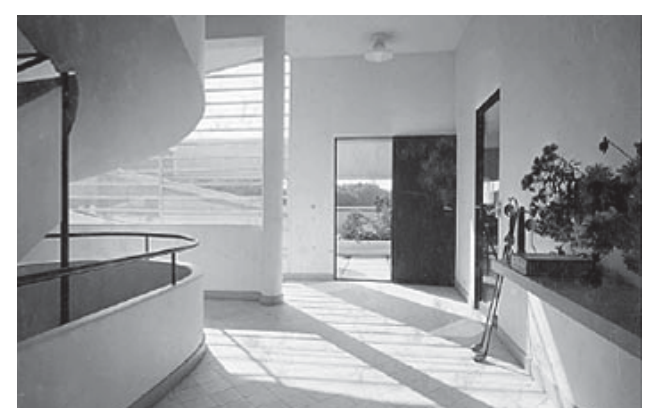

Figura 07.

Ville Savoye. Vista desde la rampa, cubierta-jardín. Fotógrafo: Le Corbusier, 1929. incorporados intencionalmente. Por ejemplo, en la fotografía del vestíbulo se puede ver un sombrero y un abrigo apoyados sobre la mesa. Estos objetos son los únicos en la escena, pertenecientes a una persona, y fueron colocados adrede por el arquitecto, por el contrario el resto del interior aparece desprovisto de elementos personales del habitante, donde el objeto arquitectónico se presenta limpio y puro.

En las fotografías de la azotea se reitera el recurso de incorporar objetos personales. Sin embargo, la ubicación de dichos objetos no fue arbitraria, se puede ver que se encuentran apoyados en el alféizar exagerado del hueco (ventana) de la fachada norte que se visualiza apenas se arriba por la rampa, considerado el punto culmine de la promenade. La fotografía fue sacada desde el lado opuesto al espacio contenido, una ubicación forzosa para el fotógrafo, ya que éste se encontraba en el pequeño espacio de azotea entre el muro y el vacío. La intención no era incomodar al fotógrafo, sino obtener una imagen que cuando el espectador la contemplase, se sintiera excluido de la posesión del espacio. La Ville Savoye se pertenecía a sí misma y nadie podía apoderarse de ella, ni siquiera su propia imagen.

Por otro lado, se puede ver como las líneas de los volúmenes puros que ocupan la fotografía fugan hacia un punto que se pierde en la organicidad de los árboles. En la Ville Savoye nada queda liberado a la voluntad del usuario, la arquitectura misma dirige las vistas hacia donde 
el arquitecto consideró que había que hacerlo: el hueco remarca la porción de paisaje que se debe contemplar y las líneas fugan hacia donde se debe mirar. Esta gestión de la realidad, no sólo se da en la Ville Savoye sino en otras obras del mismo Le Corbusier, y se logra en todos los casos a través de la figura de la ventana.

La ventana era un recurso utilizado por Le Corbusier para obtener una visión dinámica de sus edificios. En algunas fotografías del arquitecto, se puede observar como estando en un espacio, ya sea interior o exterior, a través de la ventana, se puede conectar visualmente con el espacio siguiente, y a través de otra abertura, se conecta el espacio siguiente con el contiguo de éste. El espectador se encuentra en el interior, sin embargo está vinculado a la rampa a través de un hueco, a la azotea a través de la ventana y por último al horizonte a través del hueco en fachada. De este modo, Le Corbusier empujaba al ocupante a continuar moviéndose, a desplazarse constantemente por el edificio, no le daba oportunidad de sentirse habitante, sino que lo condicionaba a ser un eterno visitante.

Por último, otro significado atribuido era la ventana como una lente que captaba imágenes del paisaje. Pero la ventana al final era también la fotografía misma, como una especie de marco que contiene a una vista determinada. Por lo tanto, la casa en sí, se transformaba en la cámara fotográfica, como afirma Colomina (2010) "la casa es un sistema para tomar fotografías. Lo que determina la naturaleza de la fotografía

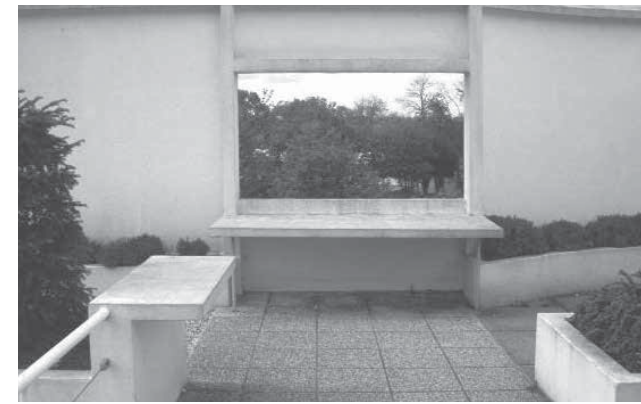

Figura 08.

Ville Savoye. Vista desde azotea hacia el norte. Fotógrafo: Le Corbusier, 1929.

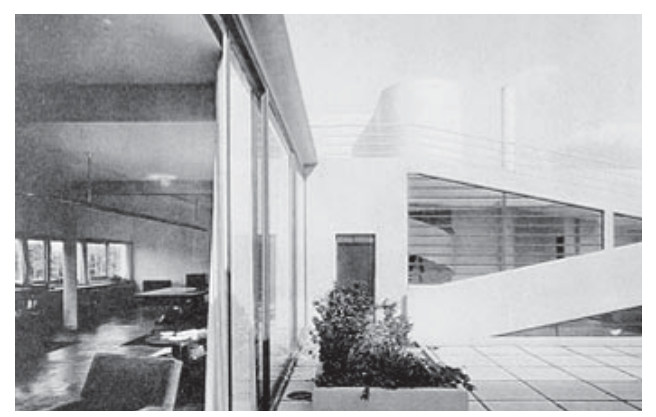

Figura 09.

Ville Savoye. Vista desde interior hacia la azotea. Fotógrafo: Le Corbusier, 1929.

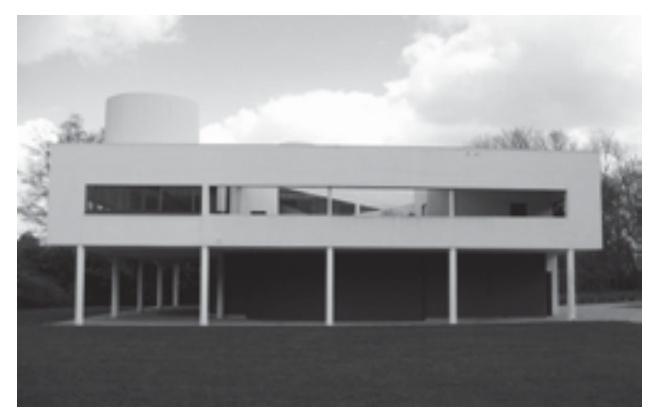

Figura 10.

Ville Savoye. Vista Frontal, Fachada oeste. Fotógrafo: Julia from Bavaria, 2008. 
es la ventana" (p. 181). La ventana horizontal se comportaba como un objetivo, que podía ser diafragmado a voluntad, ya que se ampliaba o se acortaba de acuerdo a las necesidades de luz que requería el espacio o a la porción de paisaje que se quería abarcar (Le Corbusier, 1999).

Un aspecto particular de la Ville Savoye, es que en lo exteriores (terrazas) se levantaron muros, ahuecándolos en sectores particulares, con el fin de controlar las vistas hacia el paisaje. Le Corbusier pensó las falsas ventanas, como marcos que gozaran de protagonismo tanto por dentro como por fuera de la casa. Por ejemplo, si se observa desde fuera la fachada oeste, se puede ver a través de la falsa ventana el sector de la terraza y más en profundidad el sistema de rampas. En cada cuadrante definido entre pilar y pilar, se manifiesta una escena diferente, condicionada por el juego de planos y las líneas diagonales que definen las rampas. El antepecho y el dintel, generan una sombra que recorre todo el borde el hueco, a modo de resaltar su condición de marco.

Si bien dentro del marco, todos los planos parecen estar contenidos en la misma dimensión, las sombras que arrojan uno sobre otro delatan su yuxtaposición. Le Corbusier sentía una gran atracción por representar su arquitectura de una forma plana, como si se tratase de un cuadro cubista, ya que al convertir el objeto arquitectónico en plano, se hacía más "denso en datos y dimensiones espaciales y temporales" (Zaparain, 2005, p. 64). Se trataba de un modo de ver, análogo al de la fotografía, que comprimía en un mismo cuadro distintos planos de la realidad. Una gran profundidad de campo permitía al espectador ver en el mismo plano situaciones distantes (Zaparain, 2005) y para alcanzar dicha profundidad era necesario recurrir, en términos fotográficos, a una menor apertura del diafragma, en términos arquitectónicos, a la división de la ventana.

\section{JULIUS SHULMAN: EL FOTÓGRAFO DE ARQUITECTURA}

Luego del fin de la Segunda Guerra Mundial, los siguientes quince años Estados Unidos se vio inmerso en un período de prosperidad, que se caracterizó por el estilo de vida suburbano conocido como el american way of life (Ellis y Guettler, s.f.).

El territorio americano actuó como consumidor y traductor de la arquitectura que se estaba desarrollando en Europa. En un principio, el lenguaje arquitectónico no fue aceptado para programas de vivienda, por lo cual los fotógrafos de arquitectura debían atraer a los espectadores para poder establecer la imagen moderna en la costa oeste de Estados Unidos. Mientras Schindler y Neutra establecían las bases del Movimiento Moderno en California, Shulman lo inmortalizaba a través de las fotografías (Bricker y Zilch, 2009).

Tal como lo plantean Rosa y McCoy (1994), según Shulman, el fotógrafo de arquitectura es el 
comunicador a través del cual el diseñador puede expresar el espíritu y la naturaleza de sus productos. El fotógrafo de arquitectura es el encargado de venderla y, por lo tanto, las fotografías deben exceder los límites meramente arquitectónicos para transformarse en el elemento mediático entre el objeto fotografiado y el espectador. Por esta razón, Shulman vendía la arquitectura moderna como un producto de la tecnología, el progreso y el consumo (Rosa y McCoy, 1994).

Resulta imprescindible que el fotógrafo logre transmitir las intenciones del diseñador a través de la composición, la iluminación y otras técnicas fotográficas. Por lo tanto, Shulman (1977) subrayaba la importancia de que el fotógrafo comprendiera el diseño e identificase los elementos sustanciales para transmitirlos de manera clara al espectador sin olvidar que cada publicación debía ser un eye-stopper, de modo que, en primera instancia, llamen la atención los aspectos de diseño específico de la fotografía, para que luego el espectador se interese por los motivos arquitectónicos. En otras palabras, una de las principales funciones que asumió Shulman fue crear la imagen de los proyectos que fotografió, para lo cual debió ensamblar la planta, el entorno y los elementos significativos de diseño en una fotografía cuya composición fuera atractiva. El fotógrafo muestra a través de sus composiciones los ideales del sueño californiano, colocando a la arquitectura en un segundo plano e incluyendo personas en las escenas para mostrar cómo podían ser utilizados los espacios (Shulman, 1977). De esta manera Shul- man explicaba a través de medios visuales los códigos del estilo de vida americano y transforma a la fotografía de arquitectura en una "fábrica de sueños” (Fernández-Galiano, 2013, p. 12)

La mayoría de las fotografías tomadas por Shulman fueron publicadas, a partir de 1938 , en la revista arts and architecture. Hacia 1942 el nombre de Shulman aparecía como uno de los tres fotógrafos oficiales de la revista. Arts and architecture fue una publicación reconocida por el programa que lanzó en 1945 para la construcción de las Case Study Houses (Rosa y McCoy, 1994).

\section{CASA EAMES $\left(\mathrm{N}^{\circ} 8\right)$ - CHARLES EAMES}

Los Eames asumieron que la vida era un anuncio publicitario y que por lo tanto cada ciudadano vivía como si estuviera a punto de ser capturado mediáticamente. La vida doméstica se convirtió en un objeto comercializable a través de las imágenes del good life a las cuales se podía acceder a través de las revistas especializadas. Por esta razón la arquitectura debía ser un "amortiguador y reorientador y debería proporcionar el necesario descanso de las complicaciones y problemas de la vida cotidiana" (Koenig, 2005, pp. 35-36). Según Colomina (2007), para los Eames la arquitectura de la casa se conformaba a partir de la reorganización constante de los objetos que había dentro de ella, dependiendo de las actividades que los usuarios Ilevaran a cabo, por lo que el espacio se definía a través de los detalles de la vida cotidiana. 


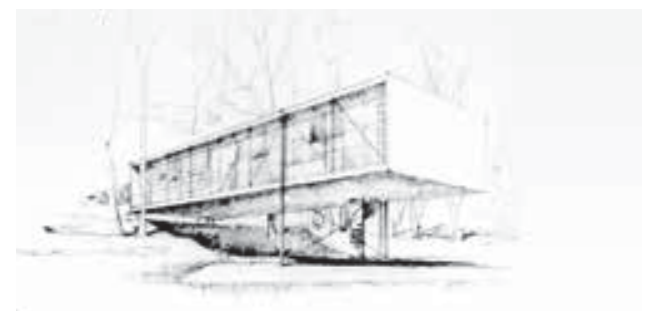

Figura 11

Proyecto inicial CSH\#8, Charles Eames, sin fecha.

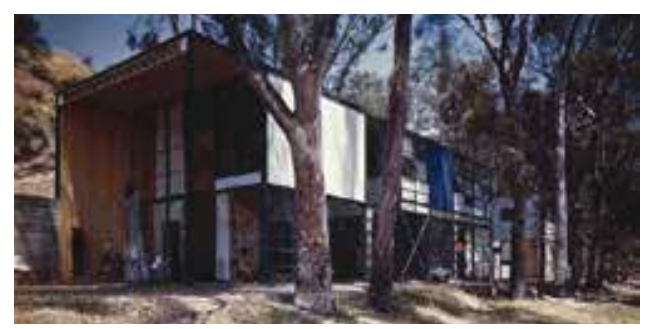

Figura 12.

Proyecto definitivo CSH\#8, Charles Eames.

Fotógrafo: Julius Shulman, 1968.

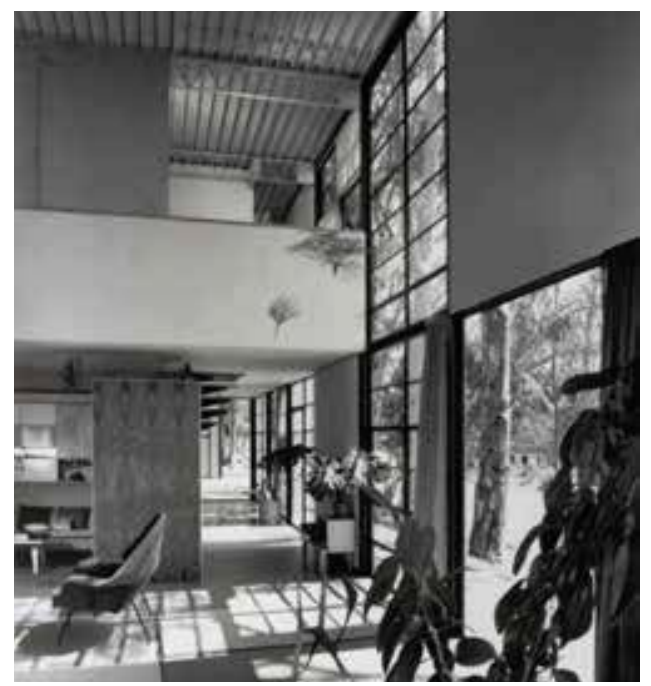

Figura 13.

Vista de la escalera en el estudio-taller. Fotógrafo: Julius Shulman, 1968.
Los Eames utilizaban los objetos que coleccionaban de viajes y de exposiciones para crear un collage espacial que mutaba constantemente. Por esta razón, el diseño de la CSH\#8 ofrecía la flexibilidad necesaria para que éstos pudieran organizar la casa por sí mismos, ya que los elementos estructurales, que son casi imperceptibles, son los únicos objetos fijos.

En la composición de las fotografías del interior de la vivienda, Shulman deja en evidencia el abandono del sándwich miesiano, donde el enfoque horizontal queda determinado entre las losas del suelo y del techo. En la CSH\#8 las paredes, el piso y el suelo cumplen el mismo rol y por lo tanto comparten funciones. Por un lado, el piso es tratado como una pared que fue enmarcada con alfombras y baldosas y a su vez, desde el techo cuelgan cuadros horizontalmente. Para atribuirle la misma importancia a todos los elementos, las fotografías fueron tomadas desde ángulos bajos (Colomina, 2006). El mobiliario fue dispuesto intencionalmente de modo que no sobresaliera individualmente, sino que su composición general y sus texturas fueran el foco de atención. Por otro lado, es importante destacar la cantidad de piso que aparece en la imagen con el objetivo de mostrar los detalles personales de los usuarios y el mobiliario diseñado por ellos mismos, como ser la Lounge Chair de madera contrachapada (Shulman y Neutra, 2000). En la misma fotografía se demuestra la linealidad del proyecto a través de la estructura que compone el ventanal y su estrecha relación con el patio y el volumen del taller 
que se logran apreciar, pero que es levemente interrumpida por la escalera revestida en madera contrachapada, que era venerada por su propio diseñador. El ventanal es interrumpido por la planta que fue expresamente colocada en dicha posición para generar, en conjunto con el respaldo del sillón, el marco de la imagen. Es importante destacar, que las fotografías de Shulman se caracterizan por tener un único punto de fuga. En este caso, la estructura del ventanal y las líneas que aparecen en el piso se fusionan en un único punto para lograr una composición más clara.

Por otro lado, el diseño arquitectónico y, en este caso estructural, está estrechamente relacionado con el interior, por lo que es imprescindible que sea plasmado a través de las imágenes. Para ello, Shulman utilizó un ángulo bajo para generar la sensación de amplitud espacial y destacar la doble altura e incluyó un sector del piso, del techo y una pared para transmitir una idea de la dimensión del espacio. A su vez, una parte de la imagen fue atribuida a la estructura que queda a la vista y al techo de acero corrugado que son protagonistas del proyecto, con el objetivo de enfatizar la forma y los materiales para realzar las estructuras industriales (Shulman y Neutra, 2000). Debido a las dimensiones del ventanal en doble altura, la iluminación artificial interior fue utilizada para equilibrar la exterior y de esa manera evitar que se generasen sombras, dado que el protagonista de la composición era el diseño del interior de la vivienda. En cada imagen realizada por Shulman el trata-

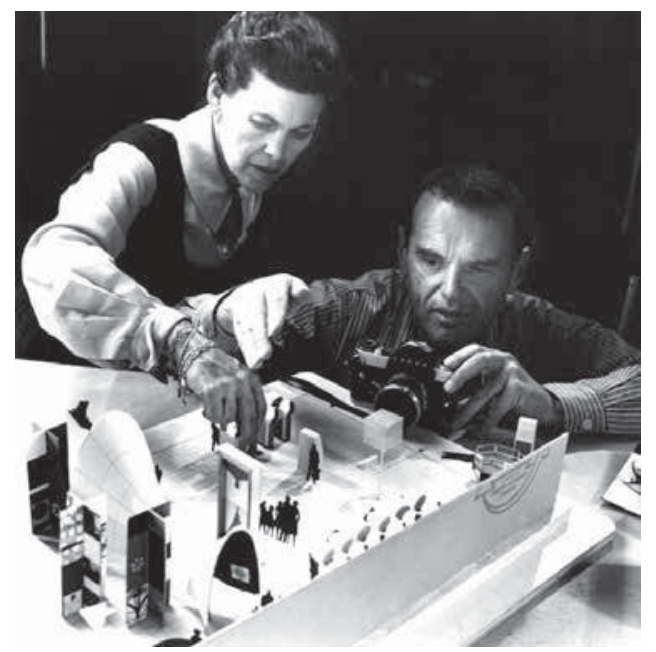

Figura 14.

Diseñadores fotografiando una maqueta. Fotógrafo: Julius Shulman, 1960.

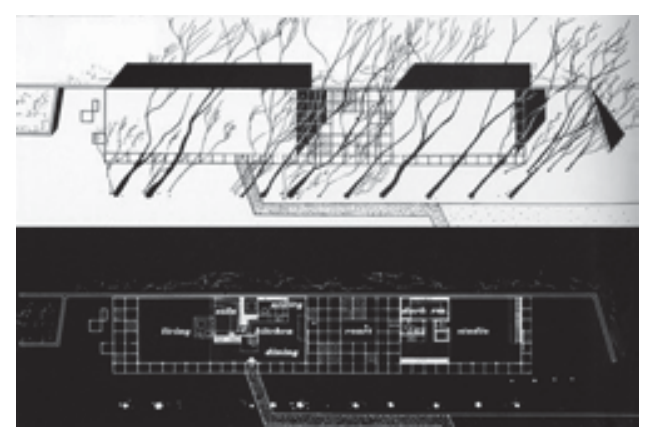

Figura 15.

Planta de la CSH \#8, Charles Eames, 1949. 
miento de la luz fue estudiado cautelosamente de antemano, ya que, según Gössel y Gehry (1998), el fotógrafo consideraba que la luz es la herramienta primordial para todo ejercicio relacionado con la fotografía, dado que las texturas, las formas, los colores y la escala son productos de su intervención.

La presencia de los usuarios en la imagen fue utilizada como forma de transferirle escala al espacio y para mostrar las actividades que se pueden llevar a cabo en éste. Tal como lo plantea Colomina (2006), tanto el vestuario con el que eran fotografiados los Eames y su ubicación en la fotografía, estaban cuidadosamente analizados, ya que la pareja pasaba a ser un objeto más de diseño dentro de la composición. Se destaca la intención del fotógrafo por captar el mismo espacio, con el mismo enfoque pero con un ángulo más estrecho y en tonos blancos y negros, que resulta en una fotografía completamente diferente, cuyo objetivo es la dramatización de la imagen para llamar la atención de los espectadores y destacar ciertos elementos (Shulman, 1977). A través de las fotografías en blanco y negro se enfatiza la forma, en este caso las líneas sólidas de la estructura y de los paneles que contrastan con las aberturas de vidrio, a través de las que se logra apreciar la naturaleza circundante. Algunos detalles como la planta, que adquiere color negro, cuya ubicación impide que el sector del ventanal adquiera tonos demasiado claros, para que el contraste con los oscuros no sea excesivo, son detalles característicos de Shulman.
El límite entre el interior y el exterior es difuso, dado que las grandes superficies de vidrio, que se intercalan con paneles, sobre los que se genera un juego de reflejos de los árboles que rodean a la vivienda. Cada panel era concebido como un marco fotográfico, en el que sucedían cosas que mutaban constantemente, lo cual reflejaba la idea de que la casa era una "escenificación sobre multipantallas” (Colomina, 2006, p. 106). Para remarcar este aspecto, un panel de la fachada sur fue sustituido por una fotografía de los reflejo de los árboles. La casa se transformó en una exposición, la cual era vista por toda la sociedad, la nueva consumidora de la domesticidad de la posguerra (Colomina, 2006).

La casa Eames es el claro ejemplo del espíritu de California en la década del 50, ya que en ella se combina el estilo de vida americano en el que la arquitectura era un objeto de consumo. Es a través de la fotografía que el proyecto es mostrado al mundo y vendido a la clase media en busca de una nueva vivienda, la cual fue desarrollada a partir de los productos creados para la guerra.

Es notoria la existencia del paralelismo entre la evolución de la arquitectura con la de la fotografía. Por un lado, los cambios en la estructura económica que se desarrollaron en primera instancia como consecuencia de la Revolución Industrial Ilevaron a la creación de un nuevo espíritu social y cultural que repercutió en todas las artes y por lo tanto en la arquitectura. De esta manera, se produjo tiempo después, a 


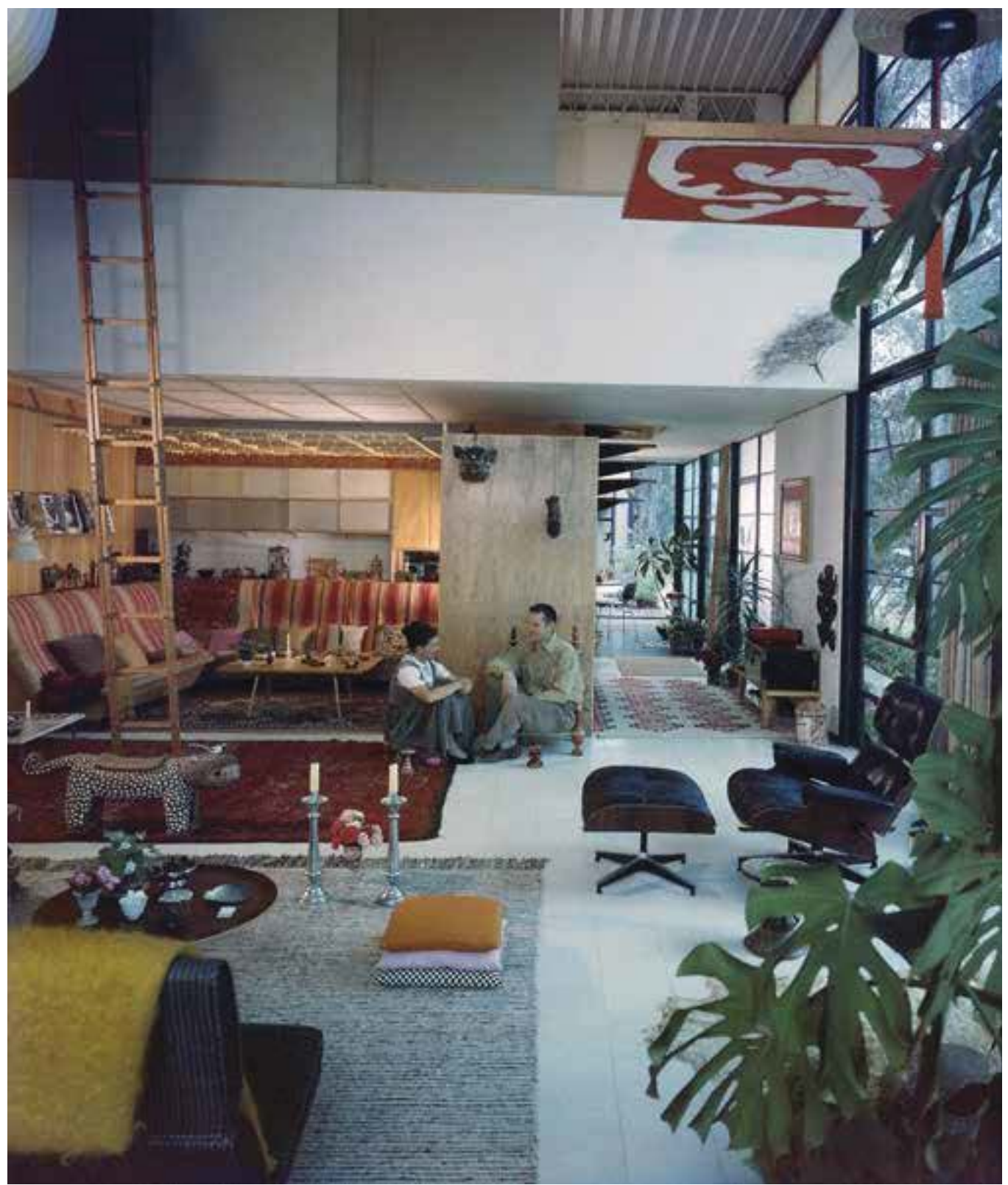

Figura 16.

Detalle living en doble altura con mobiliario seleccionado por los usuarios-diseñadores.

Color. Fotógrafo: Julius Shulman, 1958. 


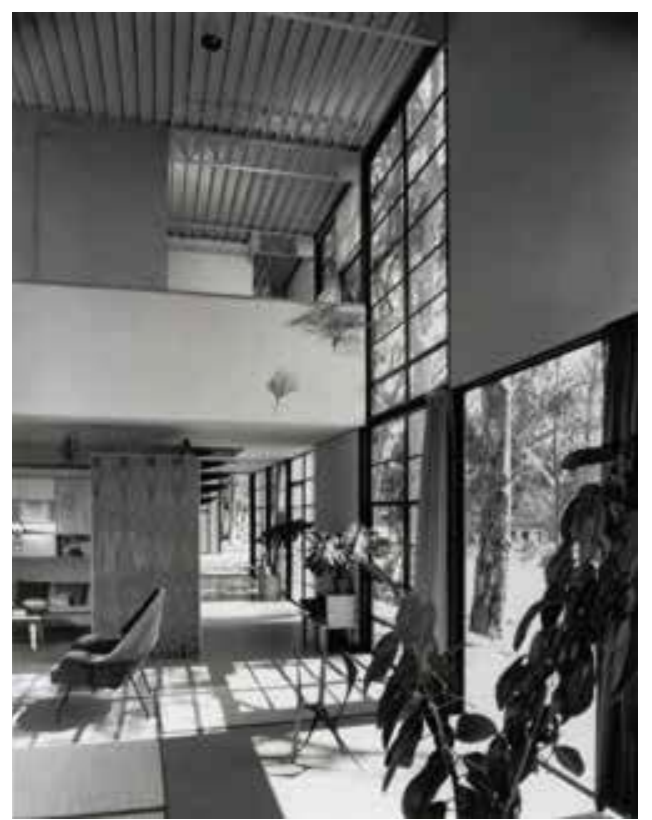

Figura 17.

Detalle living en doble altura con mobiliario seleccionado por los usuarios-diseñadores. Blanco y negro. Fotógrafo: Julius Shulman, 1950.

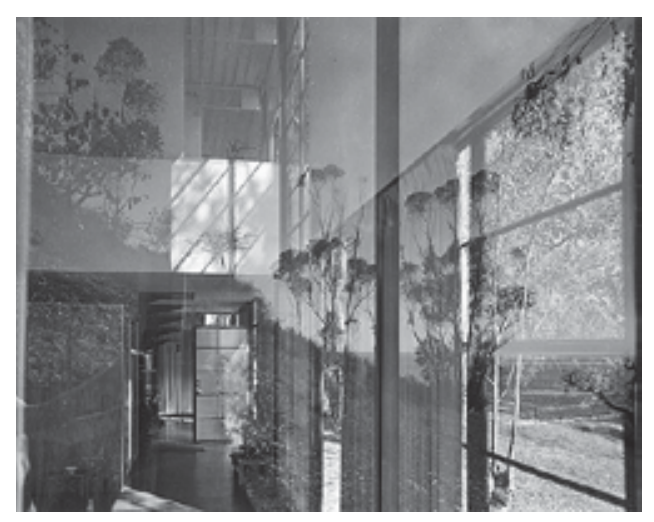

Figura 18.

Reflejos en los paneles de la fachada de la vivienda. Fotógrafo: Julius Shulman, 1958. partir de los planteos del Movimiento Moderno, un quiebre con el pasado, con las bases de la Academia, lo cual creó, no solo una nueva concepción de la composición formal y del lenguaje arquitectónico, sino que también se planteó la vivienda como una máquina de habitar para el hombre universal. Por otro lado, previo al surgimiento de la fotografía, la representación gráfica del mundo se daba a través del dibujo y de la pintura. Con la llegada de la fotografía nace una nueva forma de documentar y catalogar la realidad basada en retratar un objeto en espacio y tiempo real, ya que es un instante captado a través del ojo mecánico, lo cual valida al objeto y genera seguridad en sus espectadores. Como conclusión, los arquitectos notaron que la imagen es el medio más rápido y efectivo de hacer llegar los nuevos planteos arquitectónicos a la sociedad y encuentra en la fotografía el medio más idóneo de llevarlo a cabo. En definitiva, la fusión de arquitectura y fotografía en este período se da porque ambas se constituyen como una novedad.

La arquitectura moderna se plantea como una de sus principales aspiraciones el alcance internacional, por lo que la fotografía cumple un rol fundamental para lograr su difusión. Sin la fusión de las disciplinas, algunas obras de arquitectura no serían conocidas a nivel internacional. Por lo tanto a través de la fotografía se logra que los límites territoriales sean difusos y que la arquitectura esté al alcance de todas las personas a nivel global. 
Por otro lado, desde el punto de vista de la fotografía en sí, ésta encuentra en el objeto arquitectónico un modelo que reúne características óptimas para manifestar su propia técnica, como ser la composición espacial, el encuadre, los contrastes, los valores de las líneas y los juegos de luces. Las particularidades del lenguaje y la composición volumétrica de la arquitectura moderna le permitieron a la fotografía lucirse de un modo novedoso.

Tanto Le Corbusier como Julius Shulman utilizaron a la fotografía para crear una arquitectura ilusoria. Esta arquitectura es la que quiere ser vista o consumida por los espectadores, quienes buscan soñar con los ideales a través de las imágenes. Por consiguiente, ¿Si la arquitectura moderna no hubiese tenido la suerte de encotrarse con la fotografía, hubiese trascendido?.

RECIBIDO: 18 de octubre 2016 ACEPTADO: $1^{\circ}$ de diciembre 2016 


\section{BIBLIOGRAFÍA}

Banham, R. (1989). La Atlántida de hormigón: edificios industriales de los Estados Unidos y arquitectura moderna europea, 1900-1925. Madrid: Nerea.

Colomina, B. (2006). La domesticidad en guerra. Barcelona: Actar.

Colomina, B. (2007). Reflexiones sobre la casa Eames. Revista de Arquitectura, 9. Recuperado el 10 de febrero de 2014 , desde, http://dandun.unav.edu/ handle/10171/18044

Colomina, B. (2010). Privacidad y publicidad: la arquitectura moderna como medio de comunicación de masas. Murcia: Cendeac

Colorado, O. (2011). Berenice Abbott: cambiando Nueva York. Recuperado el 22 de diciembre, 2013 desde http://oscarenfotos. com/2011/10/07/97/

Ellis, K. \& Guettler, E. (s.f.). A better life: creating the American Dream. Recuperado el 5 de Febrero, 2014, desde http://americanradioworks.publicradio.org/features/americandream/

Fernández-Galiano, L. (2013). El ojo codicioso: representation and its discontents. Arquitectura Viva, 153, 7-15.

Gössel, P. \& Gehry, F. O. (1998). Julius Shulman: architecture and its photography. Köln: Taschen
Koenig, G. (2005). Charles \& Ray Eames 19071978, 1912-1988, pioneros de la modernidad a mediados del siglo XX. Köln: Taschen.

Lahuerta, J. (2010). Humaredas: arquitectura, ornamentación, medios impresos. Madrid: Lampreave.

Le Corbusier. (1998). Hacia una arquitectura. Barcelona: Apóstrofe.

Le Corbusier. (1999). Precisiones: respecto a un estado actual de la arquitectura y del urbanismo. Barcelona: Apóstrofe.

Rosa, J. \& McCoy, E. (1994). A constructed view: The architectural photography of Julius Shulman. Nueva York: Rizzoli.

Shulman, J. (1977). The photography of architecture and design. Nueva York: Whitney Library of Design.

Shulman, J. \& Neutra, R. (2000). Photographing architecture and interiors. Los Angeles: Balcony Press.

Zaparain, F. (2005). Le Corbusier en la Villa Savoye: la otra 'promenade'. RA. Revista de Arquitectura, 7. Recuperado el 14 de febero de 2014, desdehttp://dspace.unav.es/dspace/ bitstream/10171/18029

Zilch, B. (Productor) \& Bricker, E. (Director). (2008). Visual acoustics: the modernism of Julius Shulman [Película cinematográfica]. Estados Unidos: Arthouse Films. 


\section{FUENTES DE IMÁGENES}

01. Recuperada de: http://www.artribune.com/ tribnews/2012/10/seguendo-le-tracce-di-lecorbusier-in-italia-guida-per-agnelli-e-olivettifolla-allopening-romano-al-maxxi-ecco-lafotogallery-di-artribune/attachment/ maxxi-_-litalia-di-le-corbusier-06/

02. Extraída de Piotrowski, A. (2012). Le Corbusier and the Representational Function of Photography. En Higgott, A. \& Wray, T., Camera Constructs Photography, Architecture and the Modern City. London: Ashgate. Pág.: 36.

03. Recuperada de: https://images.adsttc. com/media/images/586f/a053/e58e/ ce3d/aa00/018f/newsletter/157929135 60_f7306f9ff2_o.jpg?1483710524

04. Recuperada de: https://veredes.es/blog/ wp-content/uploads/2014/01/Planta-bajade-la-Ville-Savoye-con-Le-Corbusier-alvolante.-Zona-de-acceso-de-veh\%C3\%AD culos-del-Pavillon-Suisse.jpg

05. Extraída de Colomina, B. (2010). Privacidad y Publicidad: la arquitectura moderna como medio de comunicación de masas. Murcia: Cendeac. Pág.: 188.

06. Recuperada de: http://dadun.unav.edu/bit stream/10171/18029/1/P\%C3\%A1ginas \%20desdeRA07-7.pdf

07. Recuperada de: http://dadun.unav.edu/ bitstream/10171/18029/1/P\%C3\%A1ginas \%20desdeRA07-7.pdf

08. Recuperada de: http://cornelljournalof architecture.cornell.edu/MEDIA/00043.jpg
09. Recuperada de: http://cornelljournalof architecture.cornell.edu/MEDIA/00043.jpg

10. Recuperada de : https://images.adsttc. com/media/images/586f/a053/e58e/ce 3d/aa00/018f/newsletter/15792913 560_f7306f9ff2_o.jpg?1483710524

11. Recuperada de: http://betterlivingsocal. com/wp-content/uploads/2015/06/ case-study-homes-8.jpg

12. Recuperada de: https://takesunset.com/ app/uploads/2010/05/case-study-housenumber-eight.jpg

13. Recuperada de: https://i.pinimg. com/736x/d1/f9/b6/d1f9b64229011715 396d51f67ee551f0--charles-eames-raycharles.jpg

14. Recuperada de: https://i.pinimg.com/ originals/23/56/d0/2356d07e0aOb122cd 1ffa53bc2705e52.jpg

15. Recuperada de: https://workdifferent.files. wordpress.com/2011/02/case-studyhouses_eames-house_n8_charles-rayeames_1.jpg

16. Recuperada de: http://www.juliusshulman. org/images/Sam\%2OHeller\%20003.jpg

17. Recuperada de: http://www.juliusshulman. org/images/gri_2004_r_10_b187_ f005_784_13(1).jpg

18. Recuperada de: https://circarq.files. wordpress.com/2016/11/img_5824.jpg 